\title{
Foreword
}

\section{Cultural Mediations and Political Economy}

THERE IS A SHORT WAY TO STATE THE MESSAGE I GET FROM THIS wonderful set of chapters: culture mediates between economy and politics. But every term in this short statement could be debated and refined, and the authors do that carefully and thoughtfully. Especially in regard to culture, this book brings together various traditions of definition and recognizes that culture is simultaneously a horizon, a map, and a resource for actors seeking to define their political and economic goals. I appreciate the authors' opening up of key terms such as agency, interest, rationality, and collectivity. They have motivated me to think further about these terms, and rather than gloss over what the authors say about them, I add here some thoughts on these terms.

Agency has a complex and contested history in the social sciences. There is wide agreement that it implies the capacity to act on the world or, as Hannah Arendt (1958) taught us, to make something new in the world, thus making action different from mere behavior. Action in this Arendtian sense is thus always political, insofar as it seeks to make a nontrivial change in the way things appear to be. Arendt was not much concerned with culture in its disciplinary sense, but it does not take much discernment to see that her idea of action, as the initiation of something new in the world, has to do with creativity, vision, and change. It is thus deeply cultural, but it has little to do with habit, routine, or custom. It is about newness, innovation, and hope. Thus, Arendt's idea of action opens up a deep justification for thinking about culture as oriented as much to the future as to the past. As the authors in this book show in various 
contexts, culture is not the inert ballast against which economic or political action is undertaken. It is also a scheme for action, a map of possibilities, and a tool for making new arrangements in the world. Culture has everything to do with agency, since it is the broad cosmological canvas that informs and underwrites action, both individual and collective, and provides a repertoire of values to imagine or constrain action. Even if interest can be seen as informing individual action, politics is always a matter of collective action, and collective action is not possible without the navigational apparatus of culture.

Several of the chapters also take up the matter of interest, a term that is closely tied to ideas about choice, preference, and utility in neoclassical economics. It is no exaggeration to say that rational choice theory, the dominant paradigm for much recent work in political economy, is grounded in a certain idea of interest. This approach to interest ties it closely to calculation, choice, and utility maximization as motives for rational action. This is also the view that has allowed a certain kind of economic analysis to colonize many aspects of human behavior in areas as varied as marriage, suicide, segregation, crime, and more. This is a style of explanation that aims to explain everything worth explaining. And it eliminates culture by translating it into the language of preferences. Preferences are in turn seen as essential to market rationality, and market rationality is seen as the only form of rationality worth discussing. At best, culture in this view is a mechanism for bounding rationality. Through a remarkable conceptual sleight of hand, value is treated as reducible to interest, interest is made the basis of preference, and preference is treated as the explanatory key to choice. In this view, culture enriches our understanding of interest formation or preferences, but we learn nothing about culture as a generative factor, and we are not enabled to question the linear transformation of cultural values into interests. This view of interest more or less trivializes culture as an autonomous and collective system of meanings, values, and dispositions. It also dilutes the idea of collectivity.

The authors and the editor of this collection are deeply concerned about collectivity, solidarity, and community. This orientation accounts for their skepticism toward many brands of rational choice theory and their endorsement of the role of culture in economics and politics. I share their inclinations and have also worried over the years about how to define the social, the collective, and the solidarity as foundational concerns of the social sciences. What they have now prompted me to see is that in our world today, the populist right has largely captured the terrain of the social by mobilizing various 
fears, anxieties, resentments, and angers among populations that are close enough to cosmopolitan life to see its benefits but far enough from it to fear and resent it. This special focal distance from the globalized good life is a key to the followers of Donald Trump, Narendra Modi, Recep Tayyip Erdoğan, Marine Le Pen, and many other new authoritarians. This emerging global right has rewritten politics as exclusion by creating a compelling narrative of the wounds, harms, and humiliations of an imagined (often racialized) majority and by targeting various kinds of others (ethnic, religious, sexual, and racial) as the sources of their humiliation. Thus, sexual policing, moral censorship, immigration barriers, and racial superiority become a key to the cultural mobilization of the popular vote, and that vote becomes the basis for electing antidemocratic leaders. This is the death of democracy by democratic means. What this book points to is a new way of connecting value, interest, community, and inclusion by restoring the role of culture in accounting for political economy. The book goes beyond our current politics to bring in historical precedents from global commerce, the role of the Tea Party in eliminating export subsidies to firms, or the links between material and cultural values for evangelical Christians.

This approach to culture demands a rereading of the relationship between such terms as value, interest, collectivity, and agency in just the ways that the authors assembled here propose. Their chapters join the work of other scholars who argue that culture is the crucial mediator between economics and politics. But these authors also recognize that for such mediation to gain analytic and ethical traction, culture itself needs to be revisioned. As an anthropologist, I am especially receptive to this mandate. The future is as cultural as the past. And any approach to global transactions in the domain of state or market that confines culture to the past will lose the distinctive assets of the idea of culture. In this perspective, culture is the common ground for action as defined by Arendt, the creation of something new in the world. 
This page intentionally left blank 